\title{
THE VENETIAN GALEA: FROM THE WOODEN MODEL TO THE DIGITAL MODEL
}

\author{
Caterina Balletti, Francesco Guerra, Agnese Lorenzon \\ Università Iuav di Venezia, 30135 Venezia - Italy \\ (balletti@iuav.it, guerra2@iuav.it, agnese.lorenzon@gmail.com)
}

KEY WORDS: Photogrammetry, Laser Scanning, 3D Modelling, Cultural Heritage Documentation, Visualization

\begin{abstract}
:
The Venetian galea (galley), dominating the Mediterranean Sea for almost 1000 years, is one of the most emblematic and fascinating objects in the history and culture of the Serenissima Republic of San Marco, the official name of ancient Venice.

This boat has changed according to the needs and developments that have taken place over the centuries, proving versatile and powerful in military and commercial use.

Unfortunately, no complete specimen has been received, and everything that can be known about galleys derives from paintings made in different eras, in models and in some original parts, kept inside the Naval Historical Museum of Venice.

Another source are some manuscripts, where part of the traditional shipbuilding knowledge is handed down. To understand a galley it is necessary to understand which techniques were used by the proti (directors of the ancient shipyard) which differ substantially from the current design.

These techniques were the synthesis of knowledge handed down from person to person and which did not make use of design drawings such as are used today. To obtain the reconstruction of a galley, lacking complete original drawings, we collected and analyzed different documentation that testified the ancient forms.

The presented work aims to reconstruct a digital model of a galea starting from the photogrammetric and laser scanning survey of a wooden model of the hull of half of a 25-bench galley of the mid-seventeenth century. The surveyed maquette and brought back to the real scale was integrated by some artifacts present at the Naval History Museum of Venice, surveyed with photogrammetric techniques and laser scanning too.

In this way a hypothetical configuration was reconstructed (by synthesis of collected and historical data) which shows the shape that this boat could reasonably have had. The result is a digital model, then printed to the scale, obtained by three-dimensional modeling starting from the point clouds of the maquette and the original artifacts. This final model has been compared with all the iconographic and documentary sources for its historical validation.

The results obtained were used for a set-up aimed at enhancing the museum, because it was intended for a large audience.
\end{abstract}

\section{INTRODUCTION}

Documentation of Cultural Heritage $(\mathrm{CH})$ should be a high priority because it has an essential and irreplaceable part of the preservation cycle. It's critical that $\mathrm{CH}$ should be documented accurately and constantly prior to any physical harm or loss that might impair its integrity, to keep detailed records of any cultural asset that contains all the proper data and information for understanding the object in question and leads to the adoption of the best practices for safeguarding it (Stylianidis et al., 2008, Stylianidis, 2019).

In the last few years, Geomatics has developed new image- based and range-based techniques and strategies for digitalizing Cultural Heritage $(\mathrm{CH})$ in order to answer to this need of accurate documentation and allowing not only to analyze the shape, geometry and position of any artifact, monitoring it over time, without necessarily coming into contact with it, but also understanding and explaining its history and relating it to the traditions of a place (Balletti et al. 2018).

As confirmed by major projects such as Europeana and "Horizon 2020 Reflective Societies 7-2014: Advanced 3D modelling for accessing and understanding European cultural assets", countless interdisciplinary projects, involving computer graphics experts, industrial engineers and personnel specialised in the documentation, conservation and use of $\mathrm{CH}$, have also achieved excellent results. In essence, a digital archive of the state of fact of an artefact can be obtained and it can be used for various purposes, remodeled, or remain safely stored.
The digitalization of $\mathrm{CH}$ must start with a survey phase, the result of which is a digital model that is a virtual replica of the object and is as detailed and accurate as current technologies permit. Obviously, each method has its own advantages and limitations and must be chosen to ensure metric survey data is both appropriate and 'fit for purpose': the scale of reduction and its own characteristic of the object must be taken into consideration. Geomatics techniques (multi-image photogrammetry; laser scanners; etc.) are successfully used in various application fields and with multi-scale approaches: they can record the topography of a large landscape distances, as well as small incisions on surfaces. Thus, the surveying process provides a virtually scaled model that is coherent in metric terms and enriched with the information regarding the aesthetic appearance of the material and reflectance properties (Chiabrando et al.2018; Andrews et al. 2015). In this framework, GAMHer (Geomatics data Acquisition and Management for landscape and built Heritage in a European perspective), which is a 3-year project financed under the Italian PRIN 2015 framework (Progetti di Ricerca di Rilevante Interesse Nazionale), is a collaborative project that aims at exploiting and validating Geomatics algorithms, methodologies and procedures in the framework of new European regulations, which require a more extensive and productive use of digital information, as requested by the Digital Agenda for Europe as one of the seven pillars of the Europe 2020 Strategy.

The project is working at the realization of tools and guidelines for a data acquisition/processing workflow of images towards a 


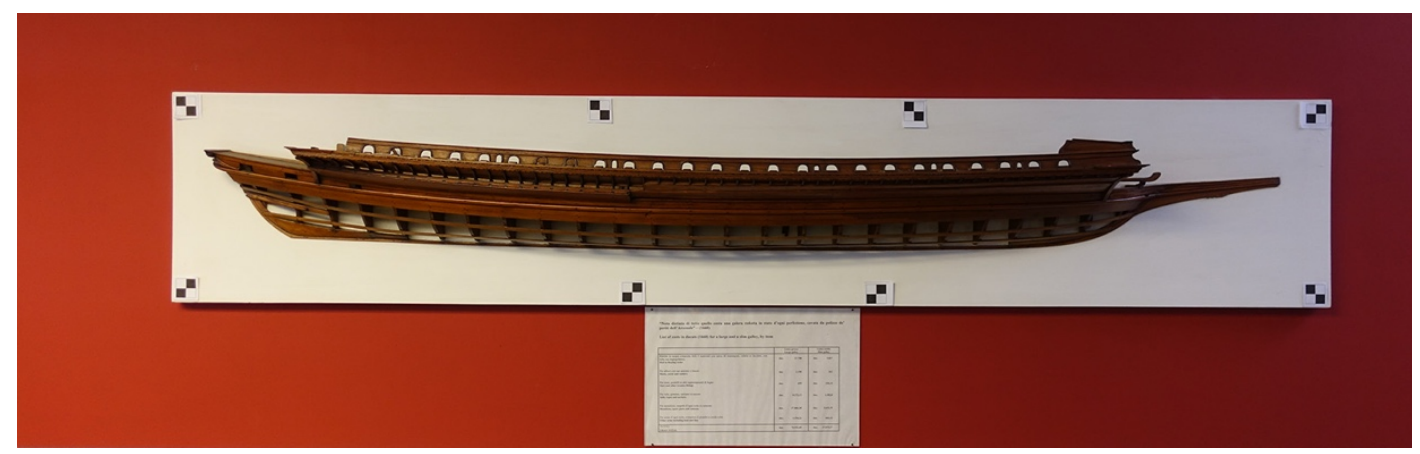

Figure 1. The half model of the galea

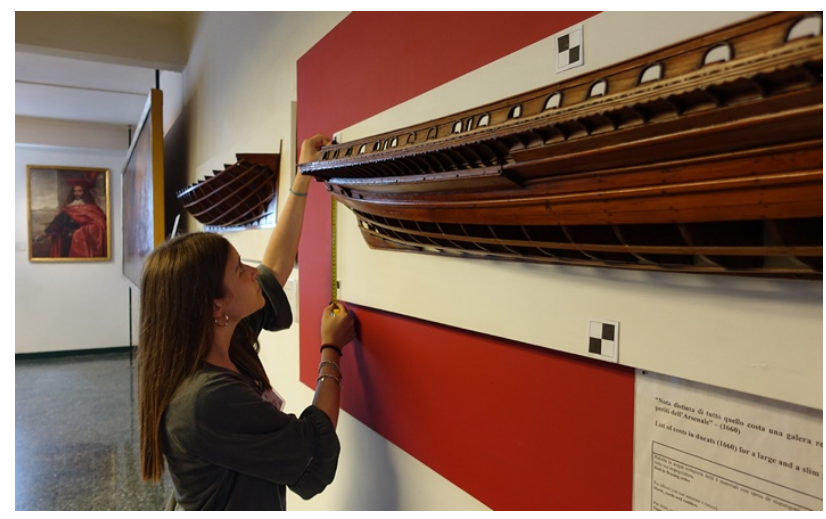

Figure 2. Detail of the half model

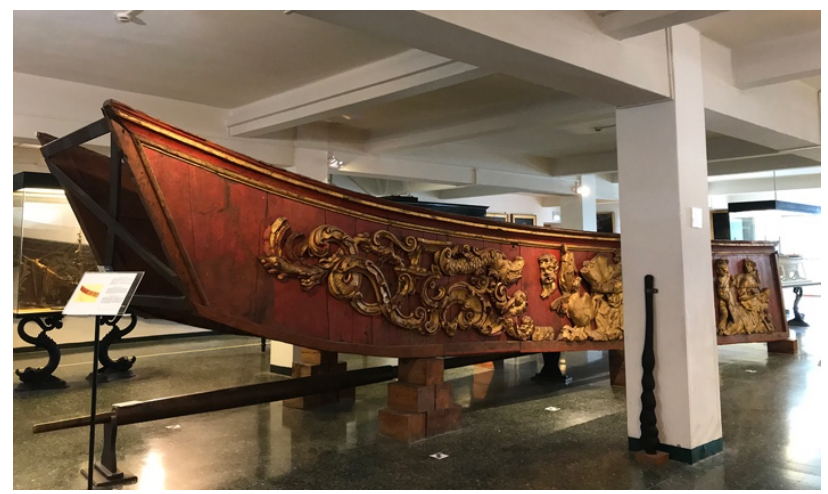

Figure 3. The cortelà, the two stern sides

reliable and accurate output for real, cost effective and productive work. (Bitelli, et al., 2017; Bitelli et al., 2019).

The project also addresses the importance of creating physical copies of $\mathrm{CH}$. This new way of thinking about representation, which also implies the production of replicas to replace artefacts, necessarily leads to reconsider the concepts of "original" and "authentic": exact replication is not possible, in terms of accuracy, but what can be achieved is a certain degree of adherence between the two realities, that is, a high resolution reproduction through different $3 \mathrm{D}$ data acquisition techniques. Moreover, the intersection of different fields of research, and means and techniques of communication, has also given rise to new forms of representation and access of $\mathrm{CH}$. The association of printed copies and other media, for example, can overcome the "static" nature of the traditional physical model, which tends to restrict the modelled object to a specific historical moment (Galeazzo 2017; Balletti et al., 2016; Ballarin et al. 2019).

It is precisely from this research context that the work presented here has developed and which has as its object the galea (galley), one of the most emblematic and fascinating objects in the history and culture of Venice and its maritime tradition.

In fact, there are no drawings and the knowledge available is fragmented. Also in the case of the other reconstructed models, which can now be visited in the museums of Genoa and Barcelona, preliminary work has been done on the collection of ancient documents. There are no original venetian galleys maintained to this day, which has happened for high types of ancient ships, such as the ship of the line and galleons. Think of the Victory of Admiral Nelson restored and exposed in Portsmouth and which has always remained operational albeit with destinations and transformations over the centuries. Think also of the case of the Vasa in Stockholm, recovered after the sinking. The only wreck of venetian galley is the one found in the lagoon on the island of San Marco in Boccalama dating back to the thirteenth century, detected in 2001 with the support of the photogrammetry lab of Iuav University of Venice (Arici et al. 2003).

\subsection{The venetian galea}

The venetian galleys are the symbol par excellence of the military power of the Serenissima, always characterized by their tapered shape and their ability in battle and in commerce. Their propulsion system is also iconic, given by the use both of rowing and wind (thanks to the sails).

The technological path of the galleys was long, but the first important moment was the appearance of the sensile galley in the 900 , as it proposed those elements that led to the characterization of the Venetian boat compared to other maritime powers. Sensile means the type of rowing used, or that each rower maneuvered his oar.

The next step was the a terzarolo galley, characterized by the addition of a third oar for each bank, with an extension of the boats, thus offering longer benches. These galleys manifested themselves in two forms: the thin ones for military use and the big ones for commercial purposes.

By the $1500 \mathrm{~s}$, a phase of experiments for technological development began. One example is given by Vettor Fausto, who in 1529 proposed the myth of the roman quinquireme, or by Picheroni della Mirandola, with his superimposed order, and finally the galea of Lepanto by Bressan, a resounding success that will bring to subsequent changes (Hercules , 2008; Concina, 1990).

We arrive therefore at the a scaloccio galleys, the last step of this evolution, which are characterized by the clear change in the rowing system: a single oar for more people, generally 4-5 per bench. The dimensions are clearly larger, even leading to the addition of 1-2 more masts.

This is the last phase of grandeur of galleys, which will be analyzed with this work starting from the survey of a wooden model (fig.1-2), exactly the model of half boat sectioned longitudinally along its centerline, preserved at the Naval History Museum of Venice, which represents a venetian galley with 25 
benches. The maquette, built in the seventeenth century, appears to be that of a sensile type, lacking the rowing benches, the ship's wheel and the mast. It represents the design-technical part of the boat, especially for the study of water lines. Of course, this model was done by the Arsenale's specialized model makers.

Regarding the dating of the model, there are many conflicting opinions, since many date it back to the 17 th century, while others to the 18th century. Doubts are about the very refined lines and small technical-nautical improvements. Following the measures' scheme proposed by Rubin de Cervin (1985), it can be deduced how the galley, represented by the half model, could be a di linea type, which was managed by the rowing of 141 rowers (3 per bench), using 47 oars.

In addition to the maquette, to complete the reconstruction process, the survey concerned the two stern sides too (fig. 3), defined as cortelà, of a seventeenth-century Venetian general galley, belonging to Lazzaro Mocenigo, a talented seafarer who became famous during the war of Candia against the Turks in 1645 , always kept in the same museum. The importance of a ship was in fact dictated by the abundance of decorations and colors used, such as red for the background and gold for the ornaments. In this case, the cortelà consists of a single piece, with the various sculpture, isolated from each other and separately applied.

Just to gather more information on this type of ship, it was decided to visit two important European maritime-themed museums, the Galata Museum in Genoa and the MMB in Barcelona, where the reconstructions of 2 galleys on a 1: 1 scale are exhibited.

For the reconstruction of the seventeenth-century galley, the first step was to analyze all the information inherent within the surveyed wooden model site. This, in fact, it was the basis from which a shipbuilder could realize boats, having already calculated and idealized the structural elements of the ship (Da Canal, C., 1928). This is reason why only the keel (in a minimal way) and part of the deck are represented in the venetian model, being made up of main components deriving from shipbuilding calculations. Thus all the more purely decorative parts are missing, such as the carossa of aft deck (which could vary according to the needs and tastes of the Captain), the benches and the masts (only marked).

To proceed with the reconstruction of the complete galley, a series of documents had to be used to support the data obtained from the wooden model. In fact, being missing most of the deck, stern and bow elements and not describing the keel in its entirety, it was necessary to look for naval plans of other galleys, so as to be able to make up for the shortcomings. In this regard, there were 3 main documents that allowed to reassemble the ship:

- the drawings of the half shipyard model surveyed by Artù Chiggiato in 1972 (Rubin de Cervin, 1985);

- the reconstruction of the galley based on the survey always by Artù Chiggiato;

- the galley's plans done for a Capo da Mar (ship captain) by an anonymous author, preserved in the archive of the Naval Historical Museum of Venice (Giro, 2017).

The documentation obtained from the surveys and integrated with the various bibliographical and iconographic sources have therefore allowed us to arrive at the definition of a complete digital model of the galley, the starting point for the subsequent elaborations used for the knowledge of this important Venetian maritime tradition.

\section{DOCUMENTATION: FROM POINT CLOUD TO 3D MODEL}

This work has turned its attention to three different phases of the process of knowledge and communication of the galley's tradition: documentation, reproduction (digital and physical) and communication, which are very effective tools that require, however, specific approaches.

Documentation aims to provide a valid support to the knowledge of the $\mathrm{CH}$ asset. It should be considering the first and most essential step of many processes: from archiving and data sharing to analysis, to conservation interventions or dissemination, just to give some examples of application field. It's evident that documentation is a phase of a more complex process, involving several professional skills, researchers and technical experts, with different specialization in the use of new technologies and with diverse objectives (Adami et al. 2015).

The survey workflow starts from the acquisition of a point cloud (the numerical model), created by means of a photogrammetric process or laser scanning. The point cloud, in this context, is understood as a set of three-dimensional data that document an asset in its entirety, as a set of millions of 3D points measured in a given environment. It is, in fact, a series of vertices in a threedimensional coordinate system defined through $\mathrm{X}, \mathrm{Y}, \mathrm{Z}$ coordinates, which are usually associated with an RGB value and/or intensity, which provide an accurate description of the object.

The point cloud is a pivot in the acquisition process - a set of transit data requiring further processing, depending on the research needs and objectives. The raw data serve as a digital copy of the real object, a set data representing three-dimensional form, geometry, measurement and matter, which can be archived and interpreted, including in support of multidisciplinary analyses.

However, the path from the surveyed model to its digital or physical representation (virtual or $3 \mathrm{~d}$ printed replica) implies a series of steps that result in simplifications, and so the loss of conformity between the original object and its reproduction.

Final models' accuracy is the fundaments for everything concerning Geomatics (Ballarin et al. 2019) and have to be related with the same characteristics of the digital model obtained through the surveying process: it means that the precision of the final model must be evaluated in relation to the precision of the instruments used during the process. Specification must be made between models of different kinds: those produced to provide new and deeper ways of understanding $\mathrm{CH}$, particularly in museum contexts, where tactile exploration of original objects is generally prohibited and models are used for an augmented communication (VR, AR, video mapping, etc.) (Ballarin et al.,2018; D’Agnano et al., 2015; Secci et al., 2019); versus replicas intended for scientific aims, of study, analysis and conservation for $\mathrm{CH}$ objects and artworks.

\subsection{The survey}

The latest available technologies and methods in the field of 3D $\mathrm{CH}$ data acquisition take advantage of two approaches: active sensors such as the well-known terrestrial laser scanning (TLS), and passive methods such as digital photogrammetry (closerange) that nowadays are connected with the automatization of the computer vision approach using structure-from-motion (SfM) techniques (Remondino, 2011). Particularly the development of new photogrammetric computer vision technologies and the improvements in image- matching algorithms allow to achieve 3D models with a very high level of detail, furthermore the opportunity to generate a high-resolution photographic texture allows to document also the consistency of the modelled object making this technique very suitable for digitization of museum collections (Aicardi et al., 2018).

The artifacts of the venetian museum were detected by laser scanning, the Faro Focus3D, just to have a global framework, and by photogrammetry: the half model of galley, placed on a wall at a height of about 1.7 from the floor and the two cortelà sides placed in the middle of a room. Being mobile objects, in this survey, contrary to what happens for the surveys of the territory 
or structures, the identification and control of the real vertical is not significant. This made it possible not to make a topographical survey for the survey of the support points but to use only measures of distance between the targets all lying on different planes. For the half model, the plane of the masonry on which it is placed was used, while for the sides the plane of the floor was used.

The survey of the support points was carried out with the direct survey technique (trilateration) which in fact creates a planimetric network (2D) of only distance measurements. After the calculation for least squares compensation, the coordinates were found to have an average standard error of $\pm 1 \mathrm{~mm}$.

For photogrammetric survey of the 3 objects, the same compact camera was used: Sony RX 100 mark IV. This camera has a Exmor RS CMOS sensor measuring 13.2 x $8.8 \mathrm{~mm}$ which provides images of $5472 \times 3648$ pixels. The pixel size is therefore $0.00241 \times 0.00241 \mathrm{~mm}$. The camera has the Zeiss Vario Sonnar $\mathrm{T}$ lens with a $8.8-25.7 \mathrm{~mm}$ zoom focal length that has always been used in the maximum wide angle position (shortest focal length). For the survey of the model, 412 photographs were taken organized in strips. These strips were made at two different average distances from the object: at $0.35 \mathrm{~m}$ for the most distant and 0.20 for those of greater detail. The average frame scale is therefore 1:40 in the first case and 1:23 in the second. Consequently, the GSD (Ground Sample Distance) are respectively $0.1 \mathrm{~mm}$ and $0.055 \mathrm{~mm}$.
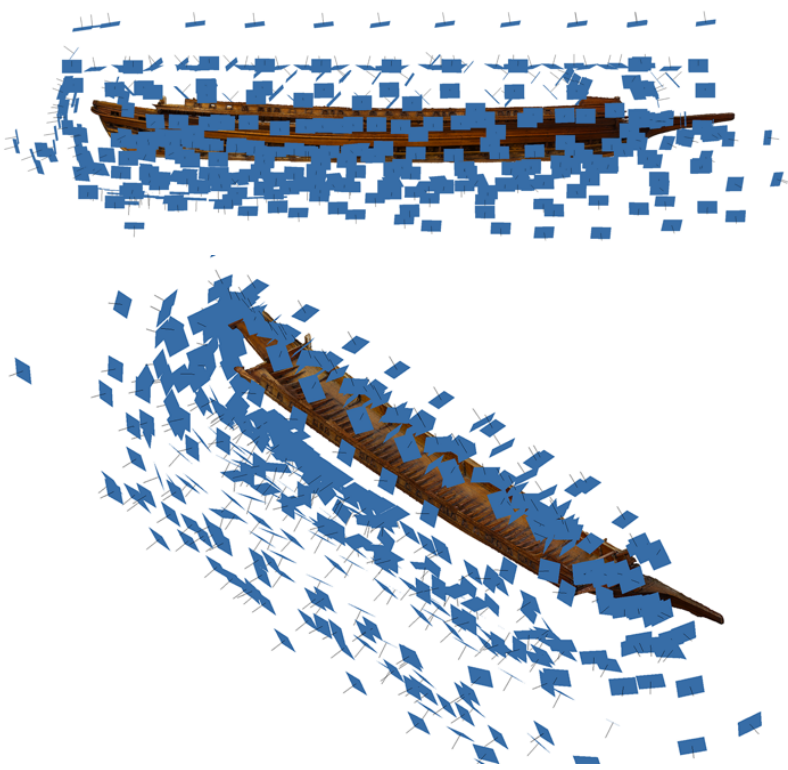

Figure 4. The photogrammetric model of the maquette

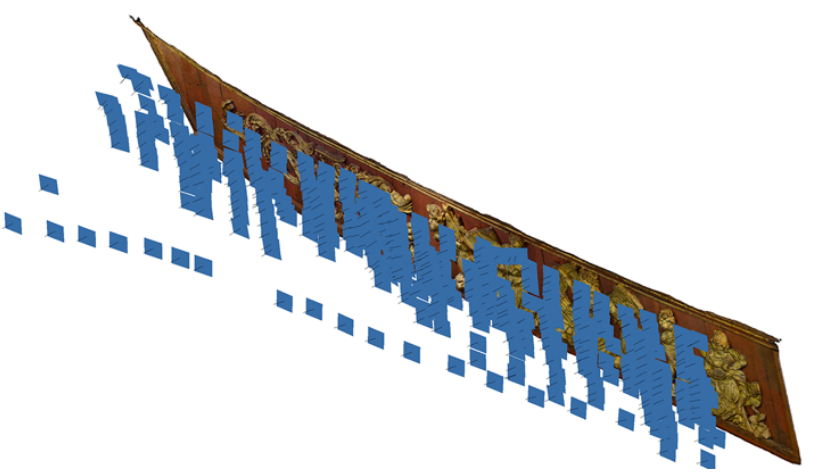

Figure 5. The photogrammetric model of the cortelà
Given the regularity of the sockets and the high multiplicity value (average number of images that capture the same point), the empirical photogrammetric precision, for streaks at a greater distance is $\pm 0.1 \mathrm{~mm}$ in the plane parallel to the frames and \pm 0.1 $\mathrm{mm}$ also for the depth. This allows to obtain a digital reproduction on a 1: 1 scale where the precision is given by the known formula $0.2 \mathrm{~mm} \times 1$ or $\pm 0.2 \mathrm{~mm}$.

The photogrammetric accuracy, however, in the case of the detection of objects of this size $(2.0 \times 0.2 \times 0.2)$ is better than that of the support points used in the absolute orientation of the block. Therefore, the residual values of the absolute orientation can be taken as an indicator of the accuracy of the survey: these are on average $\pm 1 \mathrm{~mm}$.

Similar considerations and calculations can be made for the survey of the two two "cortelà" sides. For the left side $(9.5 \times 1.5$ x $0.1 \mathrm{~m}) 425$ photographs were taken while for the right side $(9.5$ x $1.4 \times 0.1 \mathrm{~m}) 369$ images. The difference is due to the configuration of the spaces around the two objects. For both sides the images were taken with the swipe pattern. All swipes were made at two different distances from the object: at $0.75 \mathrm{~m}$ the general ones and at $0.3 \mathrm{~m}$ for more details. The camera used is always the Sony RX 100 Mark IV with the same methods and the same parameters as the case of the wooden model illustrated above. For the sides the GSB are $0.2 \mathrm{~mm}$ for the furthest strips (at $0.75 \mathrm{~m}$ ) and $0.08 \mathrm{~mm}$ for the closest ones (at $0.3 \mathrm{~m}$ ). The final precision of the models also in this case depends on the precision of the control points used in the absolute orientation and assessable by the values of the residuals of the absolute orientation: these are on average $\pm 1.2 \mathrm{~mm}$.

For the purposes of the reconstruction of the galley and 3D printing aimed at building the exhibit, the results obtained from the metric point of view are largely sufficient.

Images were processed with the software Agisoft Metashape (fig.4-5), one of the major commercial SFM-DMVR representatives currently available. The SFM method uses a number of unordered images that depict an object from arbitrary viewpoints and attempts to recover camera parameters and a sparse point cloud that represents the $3 \mathrm{D}$ geometry of a scene. Camera pose and scene geometry are reconstructed simultaneously through the automatic identification of matching features in multiple images. These features are tracked from image to image, enabling initial estimates of camera positions and object coordinates, which are then refined iteratively using non-linear least-squares minimization (Westoby et al., 2012).

The procedure of photographs processing and $3 \mathrm{D}$ model construction of the surveyed object can be describe in four well known main stage: the first one is the camera alignment: the SW searches for common points on photographs and matches them, as well as it finds the position of the camera for each picture and refines camera calibration parameters. As a result, a sparse point cloud and a set of camera positions are formed. The next stage is building dense point cloud based on the previous estimated camera positions and pictures themselves. The 3D polygonal mesh, representing the object surface based on the dense point cloud, is obtained.

\section{FROM POINT CLOUD TO AUGMENTED REPLICA}

Once the photogrammetric models and the orthophotos of each wooden models have been obtained as the basis of the $3 \mathrm{~d}$ reconstruction, it is necessary to start the mesh processing and editing using different processing software.

There are several techniques available to achieve digital models suitable for $3 \mathrm{~d}$ printing, such as the decimation of the mesh or its re-topology, but relevant issue is related to the correct geometric description of the generated surfaces. 


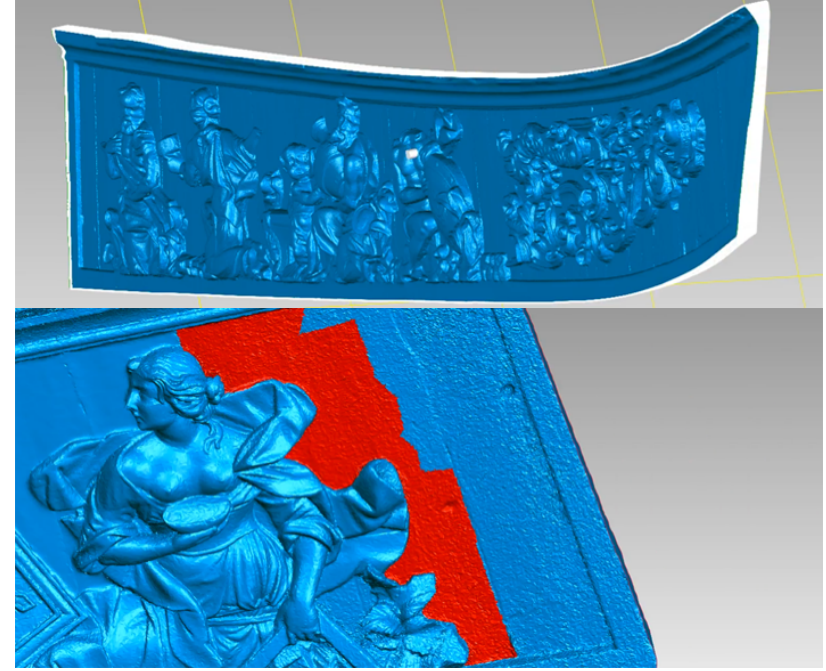

Figure 6. Cortelà 's mesh editing

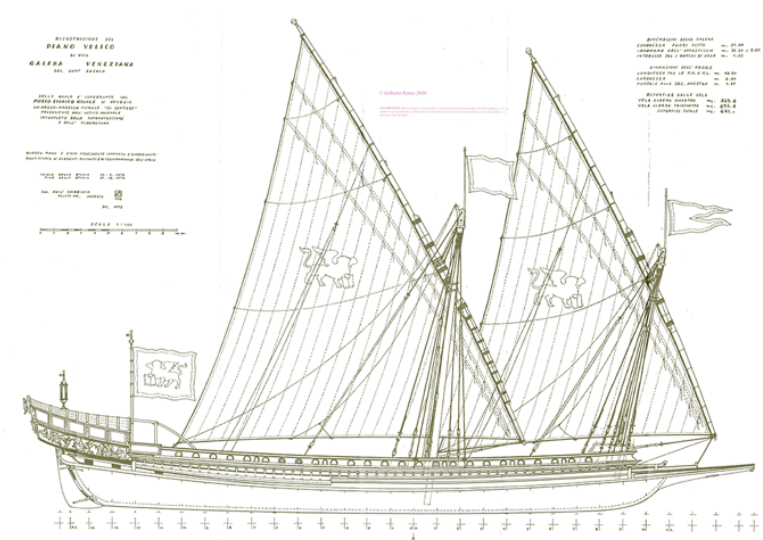

Figure 7. The Artu Chiggiato's drawing

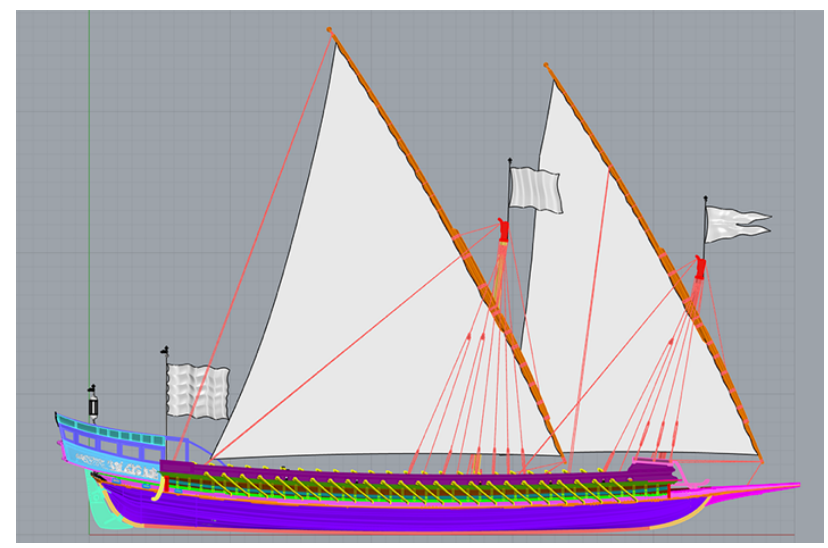

Figure 8 . The digital model integrated by Chiggiato's drawings

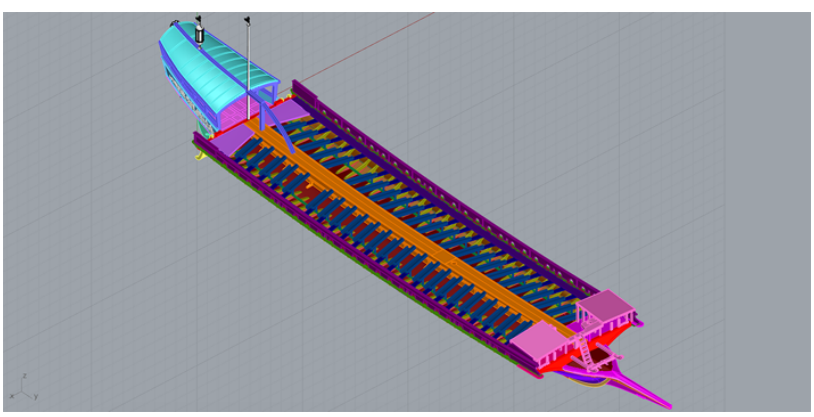

Figure 9. View of the digital model with the classification of all single elments
Although photogrammetry allows to obtain very high-resolution mesh, a critical interpretation of the geometry is needed to identify and classify each element of the hull or, generally, of the boat according to the rules of naval technique. Accurate and detailed instrumental metric acquisition of data generate a database that visually represents the acquired surfaces, but such information need to be semantically interpreted and geometrically and topologically verified to avoid the presence of holes or other errors. The mesh editing was performed in Geomagic Studio (fig.6).

For the realization of the final digital model, the augmented replica, subsequently used both for the creation of video animations and for $3 \mathrm{~d}$ printing, it was decided to use the Rhinoceros 3D software thus integrating the mesh with the drawings of ordinates done by Chiggiato (fig. 7-8-9). This made it possible to obtain the correct performance of piani / sanconi and to determine the shape of the external plating, distinguishing the slender fish shape hull. Then proceeding with the modeling of the different elements, the indications left by the drawings by Capo da Mar and by other experts were exploited. To conclude the deck part instead, in addition to the data of the wooden model, Chiggiato's interpretations were fundamental to identify and characterize the boat with its distinctive signs, such as the stern, the masts and the rembata, the two stages that form the forecastle. $3 \mathrm{D}$ printing was used to achieve the goal of showing the galley from different points of view. In recent years, the use of the 3D printer has opened up new scenarios and possibilities related to the enhancement of use and documentation in the museum and $\mathrm{CH}$. The experience of replicating objects and/or finds inside museums as copies of originals is increasingly growing (Weigert et al., 2019, Scopigno et al., 2017, Balletti et al., 2017).

To perform the final installation, a series of considerations were made on what was to be printed, and the digital models that would have enriched the video mapping. For this the following have been printed:

- the cortelà sides, in 1:20 scale, which describe the photogrammetric survey carried out at the Naval Museum, highlighting the richness of the bas-reliefs;

- the longitudinal stern part of the half galley model, in 1:25 scale, which deliberately contrasts with the incompleteness of the finding that was used for modeling;

- the central part of the reconstructed ship, in 1:25 scale, presented in its cross section including the main mast and divided into two parts, one complete with all the elements - the other characterized by the main structural parts.

Once 3D models with a proper quality are obtained, it is possible to check if the geometry will be printed correctly using additional softwares analyzing files in the Standard Triangulation Language (STL) format. This type of format is the most common in the traditional printing process, because it converts surfaces into more or less complex triangles.

$3 \mathrm{D}$ printing process was done by two spin-offs of the Iuav University itself: Proteo and FabLab. The machines that have been used are FFF printing, fused deposition modeling type, the Ultimaker 3 (printing plate: 230 x 190mm; heiht: $200 \mathrm{~mm}$; layer thicknes: 20 micron) and the DeltaWASP 2040 Turbo 2 Zen, which present a layer thickness of 50 micron which has a maximum printing plate size of $200 \times 200 \mathrm{~mm}$ and $400 \mathrm{~mm}$ in height. So models were divided into different elemts to be reproduced. The various pieces, made of PLA, the most common and resistant material that does not require high moulding temperatures and is economical, compared to ABS and Nylon (Polak et al., 2017). Once assembled, the printed parts were plastered and repainted in white, to improve the subsequent effects of video-mapping. 


\subsection{Video mapping}

The augmented replica means the interaction between digital fabrication ( $3 \mathrm{~d}$ printed model), rendering of the digital models, videos and video-mapping just to support communication and disseminating the results and the hypotheses we made about the galea, with the most appropriate tools.

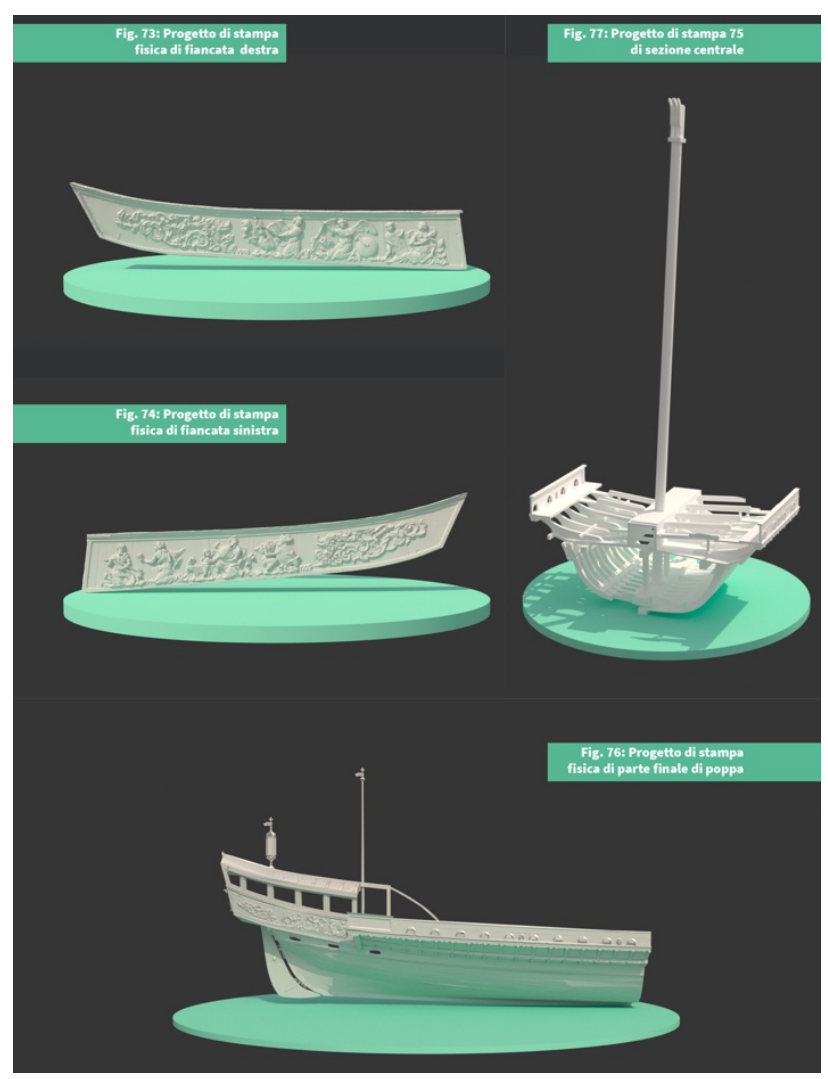

Figure 10. Renderings of the final digital model

Video projection mapping techniques are usually intended for ludic purposes and the relation between the object and the animation projected on it, is functional to entertain the audience with creative and artistic contents (Barbiani et al., 2018). Once the purpose of video mapping changes towards a communication that is intended to be more specific or even used as an educational tool, the system needs to be calibrated with a different approach. The investigation on the galea's project is part of a wider research about possible uses of video projection mapping techniques for Cultural Heritage, that involve the Photogrammetric Lab of Iuav University in Venice.

The intersection of different fields of research, and means and techniques of communication, has also given rise to new forms of representation and access of $\mathrm{CH}$. The association of printed models and other media, for example, can overcome the "static" nature of the traditional physical model, which tends to restrict the modelled object to a specific historical moment. In the last years the Photogrammetry Lab, together with other researchers, collaborated in the installation of some exhibition featuring, among other things, projections on printed three-dimensional models, recounting the stories of a place or a artifacts. With the benefit of 3D printed models and mapped projections, the nonexpert audience could "participate" to information. The combination of these two media indeed supersedes the concept of the 3D model as a frozen representation of a single historical moment. Instead, visitors can witness the continuous flow of history.

This is a form of communication which facilitates what one might call "motor-perceptual learning" in which knowledge is acquired, unmediated by text or mental reconstruction, directly through perception and motor interaction with a given reality. The play of light projecting new shapes and geometries onto the printed model surfaces gave rise to digital effects of great impact (Galeazzo, 2017).

For the exhibit, it was decided to design a panel in which the various outputs, digital and physical replicas (fig. 10-11), were collected, as if you wanted to create a set of "pictures" in the "picture": the different three-dimensional and two-dimensional representations, but also texts, showing and describing different points of view of the reconstructed seventeenth-century galley, are assembled in a single wall to be seen in their entirety. It is "a game of decompositions" in that every single panel is an end in itself and describes a certain piece of information but combined with the others it allows you to acquire a more general view of the whole, making you understand the different functions.

The installation was thus made up of $85 \mathrm{~mm}$ MDF panels on which the physical models were mounted and engraved some parts to complete the models themselves

For the video projection on the "picture", it was decided to use the EH415ST full HD 1080p projector by OPTOMA, which presents high-quality image performance at a short distance, managing to cover the entire exhibit. In order to be able to project the different contents in the panels, it was decided to place a camera at the same distance from the projector $(2.20 \mathrm{~m})$ from the installation, in order to obtain an image to be used as a basis for the video-mapping work. . The "distorted" image, in fact, was used as the basis for the creation of the video for the exhibition, processed through the AfterEffects professional-level graphic animation, compositing and video editing software. Through the use of the professional video mapping software, MadMapper, it was possible to obtain as output the video created for the installation, together with those captured during of the assembly of the printed galley, of the different three-dimensional printing pieces and the title block, so that it could be entirely editable. This occurs thanks to a warping phase in which the image exiting the projector is distorted, changing the individual coordinates of each edge, making the digital image coincide with the physical data.

The installation of the galea can be easily transported and will be presented in some exhibits on Venetian $\mathrm{CH}$ and maritime traditions (fig. 12-13). 


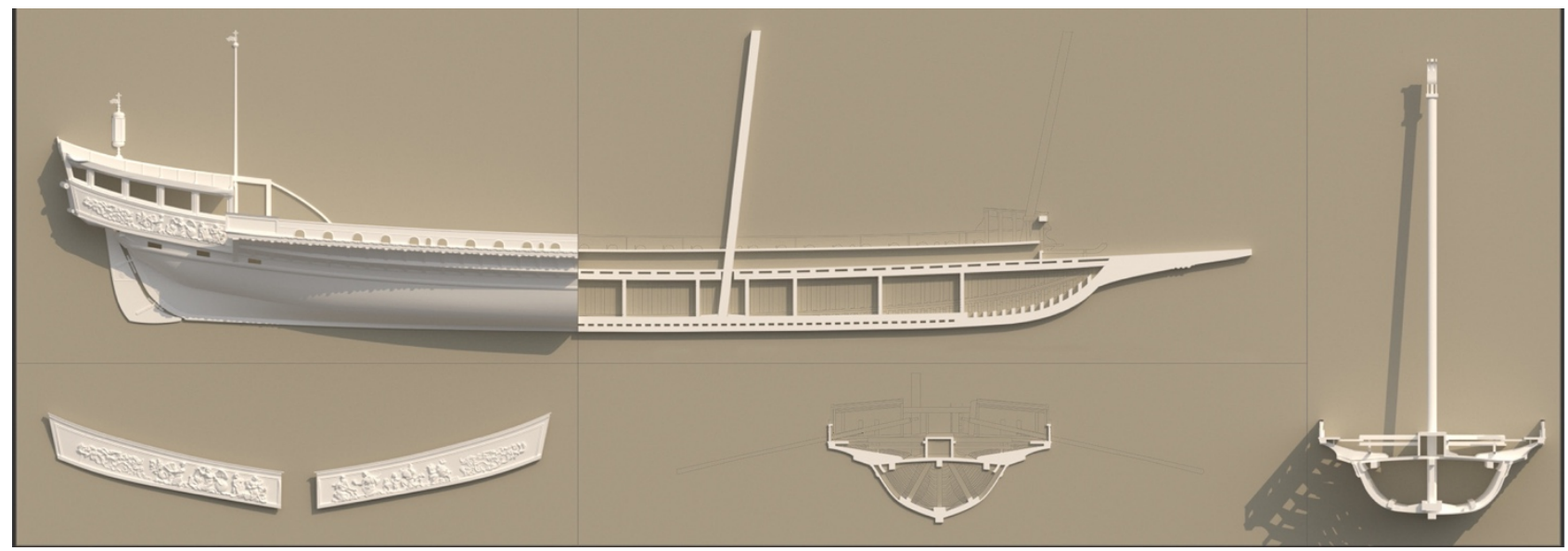

Figure 11. 3 D Printed models mounted on the installation panel

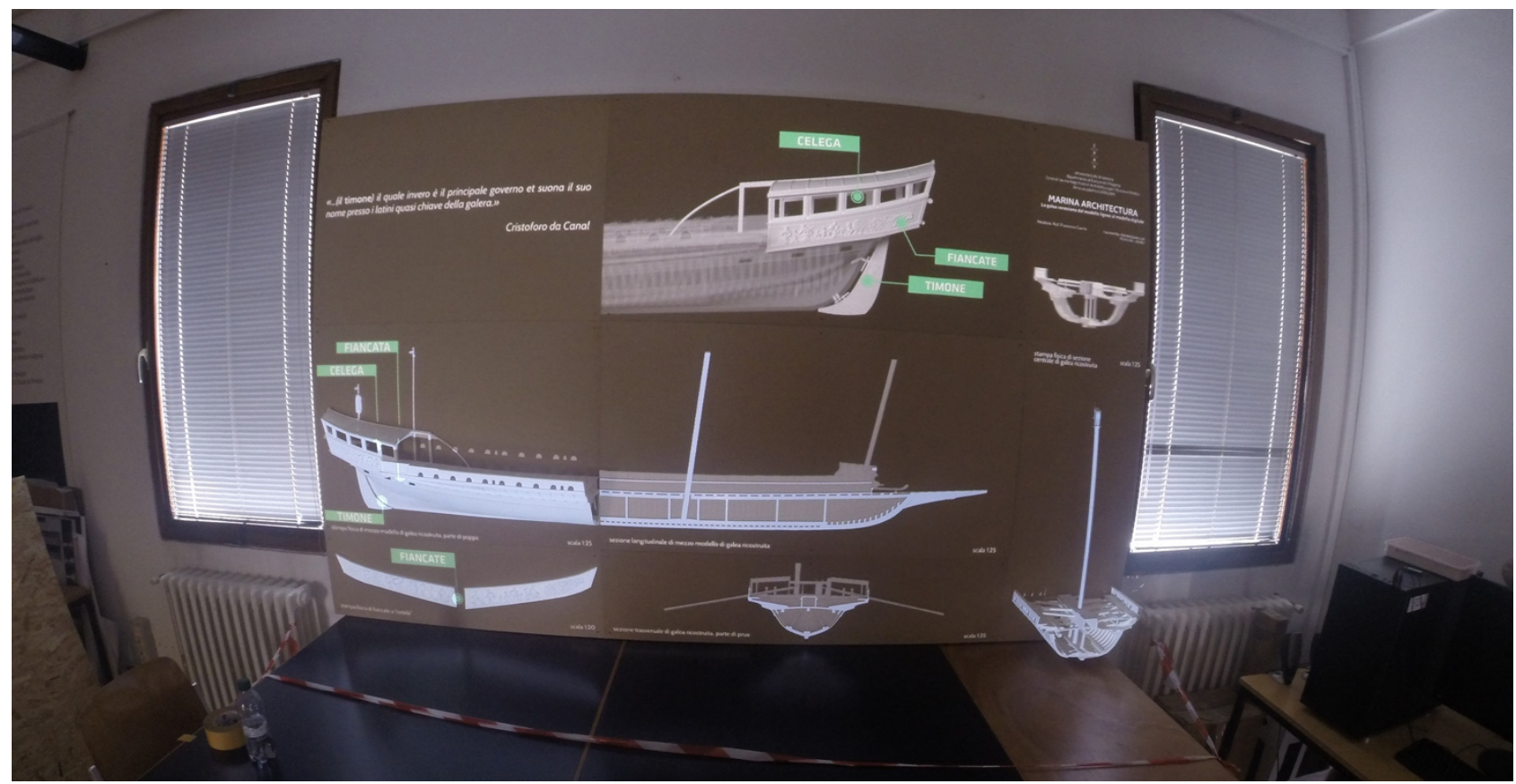

Figure 12. Simulation in the lab of the exhibit

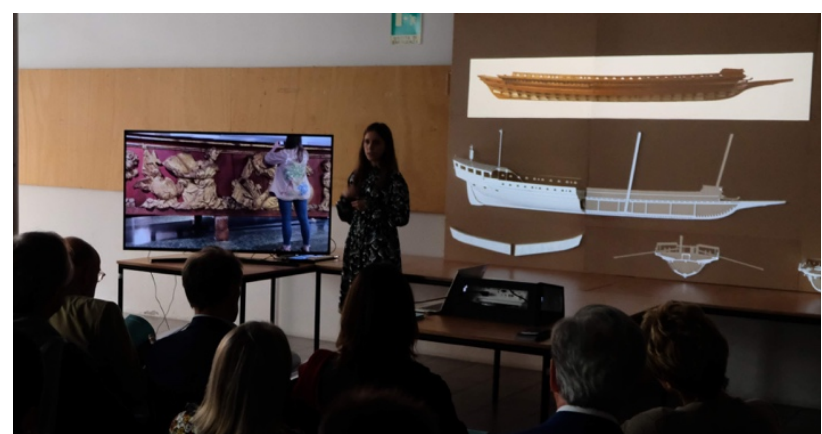

Figure 13. Presentation of the exhibit done by Agnese Lorenzon

\section{CONCLUSION}

The conservation of the galea's memory is made up of the safeguarding of different objects: manuscripts, drawings, books, ship fragments, models, wrecks. Each of these has had its own method of protection over time, the comparison between data from different sources has often been difficult. Do not forget in this regard also the different time of data storage: from some centuries of written sources to digital data of the excavations of the wrecks. The shape recording uses rigorous survey techniques such as the photogrammetric one, in which scientific rigor results from the declaration of the tools used and the methods applied. In general, it is clear that digitization, i.e. making sources digital (from texts, drawings, models, etc.) allows analysis and synthesis. Analysis because it is possible to compare and relate different sources, as in the case described, original designs and parts contribute to the synthetic reconstruction of the shape of the galley, not only from the descriptive point of view but also from the metric point of view. But the synthesis finds a way to be transmitted and therefore perceived through the use of those same digital tools used for recording. Video projection is nothing more than photogrammetric capture: the projector is described by the same internal and external orientation parameters as an image used for surveying. And the $3 \mathrm{~d}$ printing on which the information is projected is produced starting from a digital $3 \mathrm{~d}$ model, processed by numerical control machines. All this is obvious given that today, as in every age, we try to use the newest technologies to witness significant events and objects. The risk in this digital turning point is that of perceiving the great potential of the means as a flattening and homogenization. This risk is eliminated with a critical reflection on the acquisition, processing and dissemination tools after which the extraordinary possibility of integration and synthesis remains. 


\section{ACKNOWLEDGEMENTS}

This work has been carried out under the GAMHer project: Geomatics Data Acquisition and Management for Landscape and Built Heritage in a European Perspective, PRIN: Progetti di Ricerca di Rilevante Interesse Nazionale - Bando 2015, Prot. 2015HJLS7E.

\section{REFERENCES}

Adami, A., Balletti, C., Fassi, F., Fregonese, L., Guerra, F., Taffurelli, L., and Vernier, P., 2015. The bust of Francesco II Gonzaga: from digital documentation to 3D printing. In: ISPRS Annals of Photogrammetry, Remote Sensing and Spatial Information Sciences, Vol. II-5/W3, pp. 9-15. https://doi.org/10.5194/isprsannals-II-5-W3-9-2015

Aicardi, I., Chiabrando, F., Lingua, A., Noardo , F., 2018Recent trends in cultural heritage $3 \mathrm{~d}$ survey: the photogrammetric computer vision approach. J. Cult. Heritage, 32, pp. 257-266

Andrews, D.L., Bedford, J., Bryan, P., 2015. Metric Survey Specifications for Cultural Heritage. Historic England. ISBN 978-1-84802-296-6

Arici, G., Consorzio Venezia Nuova, 2003. La galea ritrovata. Origine delle cose di Venezia. Marsilio, Venezia.

Ballarin, M., Balletti, C., Vernier, P., (2018). Replicas in cultural heritage: $3 \mathrm{D}$ printing and the museum experience. In: The International Archives of the Photogrammetry, Remote Sensing and Spatial Information Sciences, Vol. XLII-2, pp. 55-62. doi.org/10.5194/isprs-archives-XLII-2-55-2018

Ballarin, M.; Balletti, C., (2019). An Application of Integrated 3D Technologies for Replicas in Cultural Heritage. ISPRS Int. J. Geo-Inf. 2019, 8, 285.

Balletti, C., Ballarin, M., Guerra, F., 2017. 3D printing: State of the art and future perspectives. Journal of Cultural Heritage. Elsevier, pp. 172-182. doi.org/10.1016/j.culher.2017.02.10.

Balletti, C., Costa, M., Guerra, F., Martinello, F., and Vernier, P., 2018. Modern and contemporary cultural heritage documentation and knowledge by surveying and its representation. In: International Archives of the Photogrammetry, Remote Sensing \& Spatial Information Sciences, Vol. XLII-2, pp. 63-67. https://doi.org/10.5194/isprs-archives-XLII-2-63-2018

Balletti, C., Galeazzo, L., Gottardi, C., Guerra, F., Vernier, P., 2016.New technologies applied to the history of the Venice Lagoon. E. Livieratos (ed.), Digital Approaches to Cartographic Heritage, Proceedings of the 11th ICA Conference, Thessaloniki, CartoGeoLab-Laboratory of Cartography \& Geographic Analysis, 2016, pp. 182-190. ISNN 2459-3893.

Barbiani, C., Guerra, F., Pasini, T., and Visonà, M.: REPRESENTING WITH LIGHT. VIDEO PROJECTION MAPPING FOR CULTURAL HERITAGE, Int. Arch. Photogramm. Remote Sens. Spatial Inf. Sci., XLII-2, 77-81, https://doi.org/10.5194/isprs-archives-XLII-2-77-2018, 2018.

Bitelli, G., Balletti, C., Brumana, R., Barazzetti, L., D'Urso, M. G., Rinaudo, F., and Tucci, G.: THE GAMHER RESEARCH PROJECT FOR METRIC DOCUMENTATION OF CULTURAL HERITAGE: CURRENT DEVELOPMENTS, Int. Arch. Photogramm. Remote Sens. Spatial Inf. Sci., XLII-2/W11, 239-246, https://doi.org/10.5194/isprs-archives-XLII-2-W11239-2019, 2019.
Bitelli, G., Balletti, C., Brumana, R., Barazzetti, L., D’Urso, M. G., Rinaudo, F., and Tucci, G.: METRIC DOCUMENTATION OF CULTURAL HERITAGE: RESEARCH DIRECTIONS FROM THE ITALIAN GAMHER PROJECT, Int. Arch. Photogramm. Remote Sens. Spatial Inf. Sci., XLII-2/W5, 83-90, https://doi.org/10.5194/isprs-archives-XLII-2-W5-83-2017, 2017

Chiabrando, F., Donato, V., Lo Turco, M., Santagati, C., 2018. Cultural Heritage Documentation, Analysis and Management using Building Information Modelling: State of the Art and Perspectives. Ottaviano E., Pelliccio A., Gattulli, V. (eds), Mechatronics for Cultural Heritage and Civil Engineering. Intelligent Systems, Control and Automation: Science and Engineering, 92. Springer, Cham, 181-202.

Concina, E., 1990. Navis: l'umanesimo sul mare, 1470-1740. Einaudi, Torino.

D’Agnano F., Balletti C., Guerra F., Vernier P., (2015). Tooteko: a Case Study of Augmented Reality for an Accessible Cultural Heritage, Digitization, 3D printing and Sensors for an Audiotactile Experience. In: The International Archives of the Photogrammetry,

Da Canal, C., 1928. Della milizia marittima libri quattro. Libreria dello stato, Roma.

Ercole, G., 2008. Le galee mediterranee: 5000 anni di storia, tecnica e documenti. Trento: Gruppo Modellistico Trentino di studio e ricerca storica

Galeazzo L., (2017). Mapping Change and Motion in the Lagoon: the island of San Secondo. K. L. Huffman, A. Giordano and C. Bruzelius (eds.), Visualizing Venice: Mapping and Modeling Time and Change in a City, London, Routledge, 2017, pp. 43-50. ISBN 978-11-3828-599-6.

Giro, L., 2017. Galee veneziane per Capo da Mar - L'eccellenza della flotta remiera della Serenissima. Gruppo Modellistico Trentino di studio e ricerca storica, Trento.

Polak R., Sedlacek, F., Raz, K., 2017. Determination of FDM printer settings with regard to geometrical accuracy. 28TH DAAAM international symposium on intelligent manufacturing and automation, DAAAM International, pp. 561-566. doi: 10.2507/28th.daaam.proceedings.079

Remondino, F., Heritage Recording and 3D Modeling with Photogrammetry and 3D Scanning, Remote Sensing, 2011, 3(6), pp. 1104-1138

Remote Sensing and Spatial Information Sciences, Vol. XL5/W4, pp. 207-2013.

Rubin de Cervin, G. B., 1985. La flotta di Venezia: navi e barche della Serenissima. The Venetian fleet: ships and boats of the Venetian Republic, Milano: Automobilia, Milano.

Scopigno, R. , Cignoni, P. , Pietroni, N. , Callieri, M. and Dellepiane, M. (2017), Digital Fabrication Techniques for Cultural Heritage: A Survey. Computer Graphics Forum, 36: 621. doi:10.1111/cgf.12781

Secci, M., Beltrame, C., Manfio, S., \& Guerra, F. (2019). Virtual reality in maritime archaeology legacy data for a virtual diving on the shipwreck of the Mercurio (1812). Journal of Cultural Heritage, 40, 169-176. 
Stylianidis, E., 2019. CIPA - Heritage Documentation: 50 Years: Looking Backwards, Int. Arch. Photogramm. Remote Sens.
Inf. Sci.,
XLII-2/W14,
$1-130$,

Spatial

https://doi.org/10.5194/isprs-archives-XLII-2-W14-1-2019,

2019.

Stylianidis, E., Remondino, F., 2008. 3D Recording, Documentation and Management of Cultural Heritage. Whittles Publishing, pp 253-368.

Weigert, A., Dhanda, A., Cano, J., Bayod, C., Fai, S., and Santana Quintero, M.: A REVIEW OF RECORDING TECHNOLOGIES FOR DIGITAL FABRICATION IN HERITAGE CONSERVATION, Int. Arch. Photogramm. Remote Sens. Spatial Inf. Sci., XLII-2/W9, 773-778, https://doi.org/10.5194/isprs-archives-XLII-2-W9-773-2019,

2019

Westoby M.J., Brasington J., Glasser N.F., Hambrey M.J., Reynolds J.M., 2012. 'Structure-from-Motion' photogrammetry: A low-cost, effective tool for geoscience applications. Geomorphology, Volume 179, pp. 300-314 